\title{
The Reset Inflation Puzzle and the Heterogeneity in Price Stickiness ${ }^{\text {th }}$
}

\author{
Engin Kara* \\ Ozyegin University
}

Forthcoming in the Journal of Monetary Economics

\begin{abstract}
New Keynesian models have been criticised on the grounds that they require implausibly large price shocks to explain inflation. Bils, Klenow, and Malin (2012) show that, while these shocks are needed to reduce the excessive inflation persistence generated by the models, they give rise to unrealistically volatile reset price inflation. This paper shows that introducing heterogeneity in price stickiness in the models overcomes these criticisms directed at them. The incorporation of heterogeneity in price stickiness reduces the need for large price shocks. With smaller price shocks, the new model comes close to matching the data on reset inflation.
\end{abstract}

Keywords: DSGE models, selection effect, reset inflation, Calvo, GTE

JEL Classification: E10, E30

\footnotetext{
${ }^{2}$ I am grateful to Ricardo Reis (the editor) and an anonymous referee for insightful comments and suggestions, which have led to a significant improvement of this paper. I also owe thanks to Jon Temple for a careful reading of the paper and helpful comments. I thank Huw Dixon, John Leahy, Ben Malin, Raf Wouters, Tony Yates and participants at the 2013 Royal Economic Society annual conference and the 2013 International Conference on Macroeconomic Analysis and Finance in Crete for helpful comments on an earlier version of the paper. I thank Pete Klenow for his answers to my questions. Ahmed Pirzada provided excellent research assistance. All errors remain my own. This is a substantially revised version of University of Bristol working paper, No. 12/632.

*Department of Economics, Ozyegin University, Nisantepe Mah. Orman Sok. 34794 Cekmekoy, Istanbul, Turkey. E-mail address: engin.kara@ozyegin.edu.tr
} 


\section{Introduction}

The New Keynesian Dynamic Stochastic General Equilibrium model developed by Smets and Wouters $(2003,2007)$, which is based on the model proposed by Christiano, Eichenbaum, and Evans (2005), has become a standard tool for monetary policy analysis. The model features several frictions such as sticky prices, sticky wages, habit formation in consumption, variable capital utilisation and strategic complementarities in price setting. Smets and Wouters (2007) (hereafter SW) show that such a richly-specified microfounded model fits the macroeconomic data such as GDP and inflation almost as well as large Bayesian VARs. Reflecting Smets and Wouters's success, an increasing number of central banks and other policy institutions have started to use the model for macroeconomic forecasting and policy analysis.

However, recent papers by Bils, Klenow, and Malin (2012) (hereafter BKM) and Chari, Kehoe, and McGrattan (2009) (hereafter CKM) have criticised the SW model on the basis that the model can explain the behaviour of inflation only when assuming implausibly large exogenous price mark-up shocks. CKM note that this is a concern since these shocks are difficult to interpret. BKM show that these shocks make reset price inflation too volatile relative to the data. The reset price is the price chosen by firms that can change their price in the current period. It is different from the aggregate price level since the aggregate price level includes the prices of firms that do not change their prices in the current period. Reset price inflation is the rate of change of all reset prices. BKM's finding suggests that the model might not be consistent with firm-level pricing decisions. This suggestion is particularly important in the light of the findings of Levin, Lopez-Salido, Nelson, 
and Yun (2008), who establish that policy recommendations that arise from New Keynesian models are sensitive to the microeconomic structure of the model even when the models explain the macroeconomic data equally well.

BKM show that two features of the model that are commonly used to generate greater monetary non-neutrality are the reasons for the failure of the model. These features are price stickiness modelled using Calvo pricing and strategic complementarities in price setting, which take the form of kinked demand, as in Kimball (1995). Without price mark-up shocks, the model with these features generates too much persistence in inflation. To match the lower degree of inflation persistence in the data, the model assumes large and transitory price markup shocks. These shocks succeed in cutting the persistence in inflation but at the cost of creating variability in reset price inflation that is far above that seen in the data.

Strategic complementarities in price setting, as in Kimball (1995), mute the response of reset prices, since firms face an elasticity of demand that is increasing in their products' relative prices and, therefore, are reluctant to pass increases in marginal costs into their prices. Inflation in the model responds even more sluggishly than reset price inflation because each period only a fraction of firms are allowed to change prices. Moreover, in the model, the firms that adjust prices are chosen randomly, implying that in the model there is no "selection effect" as to which firms change their price. This means that a firm whose price is close to the desired price is as likely to change price as a firm whose price is far away from the desired price. This feature of the model further slows the response of prices to changes in reset prices.

This paper takes up the challenge put forward by BKM. To achieve this, I 
add heterogeneity in price stickiness to the model to make it consistent with an implication of the micro evidence on prices (see Klenow and Malin (2011) for a survey). Following Carvalho (2006), the heterogeneity in price stickiness is modelled according to the Multiple Calvo (MC) model in which there are many sectors, each with a different Calvo style contract. In the MC, firms are divided into sectors according to the probability of adjusting their prices. When all hazard rates in each sector are equal, the model gives the standard Calvo model with a single economy-wide hazard rate. For the purpose of this paper, the MC is an ideal model since it enables a clean comparison of the SW model with and without heterogeneity in price stickiness. I replace Calvo pricing in the SW model with the MC assumption, in which the share of each product sector is calibrated according to micro evidence; estimate the resulting SW-MC model with Bayesian techniques using US data; and, finally, compare its empirical performance to the SW framework with Calvo pricing.

The findings reported in the paper suggest that adding heterogeneity in price stickiness to the SW model helps to overcome the two criticisms of the model. While the SW-MC model fits the macroeconomic data as well as the SW model, the variance of price mark-up shocks implied by the SW-MC is much smaller than that implied by the SW model. The SW-MC matches both the low degree of persistence in actual inflation and the low variability of reset price inflation relative to actual inflation. Importantly, this is true even though both models exhibit a similar degree of strategic complementarity in price setting.

These results can be understood in terms of the selection effect. Carvalho 
and Schwartzman (2014) analytically show that heterogeneity in price stickiness is associated with a smaller selection effect. A smaller selection effect means that fewer firms are chosen from sectors with lower hazard rates. This implies that MC firms that change their prices in a given period are disproportionately drawn from sectors with higher hazard rates. As a consequence, the price adjustment process is mainly driven by sectors with higher hazard rates. Since, with lower price stickiness, the average price levels in these sectors change more in response to temporary shocks, inflation in the SW-MC varies more than in the SW. This increased volatility of inflation reduces the need for highly volatile reset price inflation and, in turn, large price markup shocks in order for the model to match the volatility of actual inflation. My findings support the conclusion reached by Carvalho and Schwartzman (2014) that it is the degree of the selection effect that drives the properties of time-dependent models. ${ }^{1}$

The remainder of the paper is organised as follows. Section 2 presents the model. Section 3 presents Bayesian estimation results. Section 4 compares the empirical performance of the models (the SW-MC and the SW) at the macro level using different measures of relative fit. Section 5 discusses in detail what it is about SW-MC that explains the macroeconomic data as well as the SW but with smaller price mark-up shocks. Section 6 discusses the BKM critique of the New Keynesian models. Section 7 presents robustness exercises and, finally, Section 8 concludes the paper. ${ }^{2}$

\footnotetext{
${ }^{1}$ Carvalho and Schwartzman (2014) also show that their finding holds in the sticky information model of Mankiw and Reis (2002).

${ }^{2}$ The Matlab/Dynare codes used to generate the results are available in an online appendix.
} 


\section{Multiple Calvo (MC) in the SW Model}

The model presented here incorporates heterogeneity in price stickiness into the SW model using the MC approach. In this section, I will first present the equations describing price setting in the $\mathrm{MC}$ and then the remaining model equations, which are identical to a special case of the SW model with logarithmic consumption utility, no discounting and no indexation (price and wage). The first two assumptions (logarithmic consumption utility and no discounting) are made for simplicity but without significant loss of generality. ${ }^{3}$ Following BKM, price and wage indexations are removed from the model to make it consistent with an implication of the micro data that prices and wages remain fixed for several months.

\subsection{Optimal Price Setting in the $M C$}

There is a continuum of monopolistically competitive firms indexed by $f \epsilon[0,1]$, each producing a differentiated good $Y_{t}(f)$. To introduce heterogeneity in the model, the unit interval of firms is divided into segments corresponding to sectors and assume a Calvo-style contract within each sector. The sectors differ in their shares and hazard rates. There are $N$ sectors $i=1 \ldots N$ and the share of each sector is $\alpha_{i}$. In sector $i$, the hazard rate is given by $\omega_{i}$. A firm resetting its price in sector $i$ in period $t$ seeks to maximise its expected discounted profits over the life of the contract subject to the demand curve the firm faces. Using $\bar{x}_{i t}$ to denote the logarithmic deviation of

\footnotetext{
${ }^{3}$ Estimating the discounting parameter and the intertemporal elasticity of substitution does not change the results significantly. Perhaps this is not surprising as the estimates for these parameters are similar to the assumed values.
} 
the reset price in sector $i\left(x_{i t}\right)$ from the aggregate price level $\left(p_{t}\right)$, I obtain the following log-linear pricing rule for the firms in sector $i$

$$
\bar{x}_{i t}=\omega_{i} \bar{A} \bar{m} c_{t}+\left(1-\omega_{i}\right)\left(E_{t} \bar{x}_{i t+1}+E_{t} \pi_{t+1}\right)+\varepsilon_{t}^{p}
$$

where $\bar{x}_{i t}=x_{i t}-p_{t}$ is the real reset price in sector $i, p_{t}$ is the general price level and $\pi_{t}$ is inflation. ${ }^{4} \bar{A}=1 /\left(\zeta \epsilon_{p}+1\right)$ measures how responsive the firms are to the changes in real marginal cost and is determined by two parameters: $\epsilon_{p}$, which is the percentage change in the elasticity of demand due to a one percent change in the relative price at the steady state and $\zeta$, which is the steady state price-markup and is related to the fixed costs in production. $\bar{m} c_{t}=(1-\alpha) w_{t}+\alpha r_{t}^{k}-\varepsilon_{t}^{a}$ is the real marginal cost and depends on wages $\left(w_{t}\right)$, the rental rate of capital $\left(r_{t}^{k}\right)$ and total factor productivity $\left(\varepsilon_{t}^{a}\right)$. In each sector $i$ relative prices are related to the reset prices in that sector as follows:

$$
\bar{p}_{i t}=\omega_{i} \bar{x}_{i t}+\left(1-\omega_{i}\right)\left(\bar{p}_{i t-1}-\pi_{t}\right)
$$

where $\bar{p}_{i t}=p_{i t}-p_{t}$ denotes the logarithmic deviation of the aggregate price in sector $i\left(p_{i t}\right)$ from the aggregate price level. These two equations can also represent the Calvo model. Noting that $\bar{p}_{i t}=\bar{p}_{i t-1}=0$ and dropping subscript $i$ gives the Calvo model. The nominal aggregate price level in the economy is simply the weighted average of all ongoing prices. This relation

\footnotetext{
${ }^{4}$ In the MC, reset prices differ across sectors since they face different hazard rates. However, due to the random nature of the Calvo contracts, all firms within the same sector set the same price and therefore subscript $f$ has been dropped from $\bar{x}_{i t}$.
} 
implies that

$$
\sum_{i=1}^{N} \alpha_{i} \bar{p}_{i t}=0
$$

The aggregate real reset price is given by

$$
\bar{x}_{t}=\sum_{i=1}^{N} \alpha_{i} \bar{x}_{i t}
$$

Thus reset price inflation is given by

$$
\pi_{t}^{\star}=\bar{x}_{t}-\bar{x}_{t-1}+\pi_{t}
$$

where $\pi_{t}^{\star}$ is reset price inflation. The rest of the model equations are the same as those in SW and are listed in Appendix A.1.

\section{Data and Estimation Results}

As in BKM and SW, the model is estimated using Bayesian techniques. I use the same dataset and marginal prior distributions as in BKM. A brief description of the dataset can be found in Appendix A.2. Tables 1 and 2 provide a summary of the priors.

"Locate Tables 1 and 2 about here"

To calibrate the share of each sector (or product category), the Bils and Klenow (2004) dataset is used. The dataset is based on U.S. Consumer Price Index (CPI) microdata. The data are derived from the U.S. CPI data collected by the Bureau of Labor statistics. The period covered is from 1995 to 1997, and the data fall into 350 categories accounting for $69 \%$ of 
the CPI. The dataset provides the average proportion of price changes per month for each category and the corresponding category weights in the CPI. These numbers are interpreted as Calvo hazard rates. For computational ease, those 350 product categories are aggregated into 10 sectors, each with a different hazard rate $\left(\omega_{i}\right)$. To do so, the statistic provided by Bils and Klenow for each category is rounded to one decimal place and then summed across categories with the same hazard rate using the category weights. This transformation results in ten different hazard rates. ${ }^{5}$ The resulting mean age of price spells is $\kappa=\sum_{i=1}^{10} \frac{\alpha_{i}}{\omega_{i}}=3.46$. The hazard rate $(\omega)$ is estimated in the SW approach.

\subsection{Posterior estimates}

Table 1 reports the means and the standard deviations of the posterior distributions of the parameters in the SW and SW-MC models obtained by the Metropolis-Hastings algorithm. Table 2 presents the results for the shock processes.

Results reported in Tables 1 and 2 suggest that the data are informative about most of the parameters, for which priors and posteriors have different locations, shapes and spreads. Most of the estimates are similar across the two models, with an important exception. The estimates for parameters

\footnotetext{
${ }^{5} \mathrm{I}$ also estimate the model using an alternative dataset provided by Klenow and Kryvtsov (2008). Doing so does not affect the conclusions of the paper. An alternative modelling approach is to identify each product category with a sector in the model. This approach requires calibrating a 350 sector MC. When the model is re-estimated with this approach, the main results of the paper are not affected. This finding is not too surprising since, reflecting the fact that many product categories have similar hazard rates, the standard deviation of durations of price rigidity in the two distributions are similar. The standard deviation of durations are around 4 .
} 
describing the price mark-up shock process (i.e. $\sigma_{p}, \rho_{p}$ and $\mu_{p}$ ) in the SW$\mathrm{MC}$ are very different from those in the SW. At around $0.33 \%$, the implied standard deviation of mark-up shocks in the SW-MC is much lower than that of the mark-up shocks in the SW (0.91\%).

The above finding is true even though the two models have almost exactly the same average degree of price stickiness and exhibit a similar degree of strategic complementarity of firm pricing decisions. The estimated average age of price contracts (i.e. $1 / \omega)$ in the SW is 4 bi-months, while the corresponding mean in the $\mathrm{SW}-\mathrm{MC}$ is 3.5 bi-months. ${ }^{6} \bar{A}$, which measures the degree of strategic complementarity of firm pricing decisions, is almost the same in both models. It is 0.029 in the SW-MC, while it is 0.037 in the SW.

These findings bring up a natural question: why are the price mark-up shocks smaller in the SW-MC? To provide an answer to this question requires showing that the SW-MC explains inflation and the other observed variables equally well and that the smaller price mark-up shocks are not a consequence of a deterioration in the model's ability in explaining inflation and the other observed variables. This is what I do in the next section.

\section{Model Comparison}

The empirical performance of the SW-MC relative to the SW model is tested by using three measures of relative fit. The models are first compared using Bayes Factors, and then by comparing the standard deviations of the

\footnotetext{
${ }^{6}$ As noted above, the hazard rates are calibrated in the SW-MC, whereas the hazard rate in the SW is estimated. I also estimate the SW model subject to the hazard rate implied by the distribution in the MC (i.e 1/3.5). My conclusions remain unchanged.
} 
observed variables in the models and those in the data. Finally, given that much of this work is motivated by the recent behaviour of inflation, the behaviour of actual inflation during the sample period is compared to that implied by the models.

The first two rows of Table 3 report the log marginal data densities for the two models and the corresponding Bayes Factors by taking the SW model as the reference model. For the SW-MC, the log marginal data density is -712.9 , while it is -713.4 for the SW. These numbers imply a Bayes factor of around $e^{0.5}$, meaning that the SW-MC performs slightly better than the SW model in explaining the aggregate data.

\section{"Locate Table 3 about here"}

The third through eighth rows of Table 3 report the standard deviations of the observed variables in the models and those in the data. Again, as is evident from Table 3, the SW-MC performs as well as the SW in accounting for the standard deviations of the observed variables.

Turning to the behaviour of inflation, persistence in actual inflation is low, due to the sample period considered in this paper (1990-2009) (see BKM and references therein for a discussion of this point). The first-order autocorrelation coefficient for actual inflation is as low as 0.13 . This measure of inflation persistence in both models is 0.13 , that is a spot on with the empirical estimate.

\section{"Locate Figure 1 about here"}

Finally, it is instructive to compare the impulse response function (IRF) for actual inflation estimated by BKM by using an $\operatorname{ARMA}(6,6)$ process with 
those for the models. Figure 1 plots the estimated cumulative IRF for actual inflation to a $1 \%$ shock along with those for the models. The model IRFs are generated by fitting an ARMA $(6,6)$ process to the data simulated from the models, just as BKM do on the actual data. The empirical response exhibits a hump-shaped response. It builds in the first couple of periods but then gradually goes back to its initial value within 15 periods. The SW model IRF differs sharply from the empirical IRF in that the IRF in the SW builds over time, whereas in the data it returns to its long-run value. The IRF in the SW-MC is closer to the empirical pattern. Although initially the SW-MC IRF is lower than that of the data, the model IRF matches the empirical IRF closely.

\section{What Explains the Smaller Price Mark-up Shocks?}

This section explains what it is about the MC that fits the macroeconomic data as well as the SW but with smaller price mark-up shocks. Before doing this, it is useful to recap the SW case.

Without price mark-up shocks, the SW generates a degree of inflation persistence that is significantly larger than seen in the data. The serial correlation of inflation in this version of the model is as high as 0.9. Relatedly, the model inflation rate is less volatile than in the data. The high degree of persistence is a consequence of the model's assumptions of Calvo pricing and strategic complementarities. These assumptions give rise to a flat Phillips curve, meaning that changes in marginal cost have little impact on inflation and, therefore, it takes time for the changes to be reflected in prices. To bring inflation's persistence in line with the lower degree of persistence observed in 
the data, the model includes a large and transient price markup shock. This shock differs from the other shocks in that it is the only shock that does not affect inflation through marginal cost. It affects inflation through its effect on reset prices. With price mark-up shocks, the persistence of inflation is 0.13 , the same as that for the data. To understand how transitory pricemark shocks reduce the persistence in inflation, consider the effects of such a shock on inflation and reset prices. When such a shock hits the economy in period $t$, firms resetting their prices increase their prices. Soon after period $t$, the shock is completely gone and the reset prices become too high, relative to what they should be. As a result, firms resetting their price in the second period reversed the initial price increase, resulting in negative reset price inflation. So, a period of above-average reset price inflation is followed by a period of below-average reset price inflation, thus cutting inflation's persistence considerably. While this results in volatile reset price inflation, due to price stickiness, inflation does not change much. Therefore, to match the volatility of inflation, the required size of the price mark-up shock must be large. For these reasons, as noted by BKM and SW, inflation in the model is mainly explained by the price mark-up shocks.

To understand the reason why the required standard deviation of the price mark-up shocks is lower in the SW-MC, first note that adding heterogeneity in price stickiness to the model affects the price adjustment process in two important ways. First, the presence of heterogeneity in price stickiness in the SW-MC brings about a smaller selection effect. This is because in such a model firms that change their prices in a given period are not an unbiased sample of the total population of firms, as in the Calvo model. Rather, they 
are mostly chosen from the sectors with higher hazard rates. Second, the presence of the sectors with lower hazard rates in the model can significantly increase the persistence of inflation, as prices in these sectors take longer to adjust. As a result, the $\mathrm{MC}$ can generate more inflation persistence than the corresponding Calvo model. This discussion suggests that the earlier part of the price adjustment process is dominated by the sectors with higher hazard rates, while the later part of the process is driven by the sectors with lower hazard rates.

The first difference has important implications for the volatility of inflation and leads to more volatile inflation in the SW-MC than in the SW. This is because in the SW-MC sectors with higher hazard rates, the average price levels vary a lot in response to temporary shocks, as in these sectors a larger proportion of firms adjust their prices in each period. Since these sectors dominate the earlier part of the price adjustment process, the aggregate price level varies more in response to temporary shocks, leading to more volatile inflation in the SW-MC. As a consequence, the required size of price mark-up shocks to match the volatility of inflation is smaller in the SW-MC.

\section{Reset Price Inflation: Addressing the BKM critique}

This section addresses the criticism of BKM of New Keynesian models, indicating that the reset price inflation implied by the model is too volatile relative to that seen in the data. As discussed earlier, the reason for the

implausibly volatile reset price inflation in the SW model is the presence of temporary and large price mark-up shocks. My finding that the price markup shocks are smaller in the SW-MC suggests that the SW-MC may match 
the statistics on reset price inflation better than the SW model with Calvo pricing. I now consider this suggestion.

Let me first describe the problem pointed out by BKM. Table 4 reports summary statistics for reset inflation from the data and the models. Column (1) of Table 4 shows the statistics from the data and Column (2) for the $\mathrm{SW}$. The reset price inflation implied by the SW model is significantly more volatile than the data. The standard deviation of reset inflation in the model is around $1.6 \%$, a value that is 2.5 times larger than indicated by the data. The reset price inflation in the SW model is more persistent than in the data. The serial correlation of reset inflation, which is measured by its first-order autocorrelation, is -0.42 , whereas it is 0.06 for the data. The behaviour of the model's reset price inflation is different from that of actual reset price inflation also at longer horizons. To show this, BKM estimate an IRF for reset price inflation by using an $\operatorname{ARMA}(6,6)$ process, both for the model and the data. The one-year cumulative IRF for reset price in the SW is around 0.31 which is about half of what it is for the empirical IRF. Moreover, the model's one year cumulative IRF for inflation is almost four times that for reset price inflation. In the data, this ratio is only one and a half. This difference suggests that, conditional on reset price inflation, the model generates too much persistence relative to the data.

"Locate Table 4 about here"

I now evaluate the extent to which the SW-MC matches the statistics on reset price inflation. Column (3) of Table 4 reports the statistics for the SWMC. As suggested above, reflecting the lower price mark-up shocks, the SWMC closely match the data on reset price inflation. The standard deviation 
of reset price inflation is now within a striking distance of the data. It is $0.77 \%$ in the SW-MC, while it is $0.66 \%$ in the data. Heterogeneity in price stickiness increases the serial correlation of reset price inflation in the model considerably, from -0.42 to -0.19 . The one-year cumulative IRF for reset inflation almost matches that for the data. The one-year cumulative IRF for inflation is 0.51 , while it is 0.61 in the data. Moreover, at around 2 , the ratio between the one-year cumulative IRF for inflation and that for reset price inflation in the SW-MC is not far from the data's 1.5.

These findings bring up a natural question: given that the inflation dynamics in both models are similar, why is reset price inflation smoother in the SW-MC? This can be easily understood by examining aggregate reset price in the SW-MC. Aggregating equation (5) across sectors and noting that $\bar{p}_{i t}=\bar{p}_{i t-1}+\pi_{i t}-\pi_{t}$ gives aggregate (real) reset price

$$
\bar{x}_{t}=\sum_{i=1}^{N} \frac{\alpha_{i}}{\omega_{i}}\left(\pi_{i t}-\pi_{t}\right)+\sum_{i=1}^{N} \alpha_{i} \frac{1-\omega_{i}}{\omega_{i}} \pi_{t}
$$

This equation shows aggregate real reset price depends on inflation and inflation gaps (i.e. the difference between inflation in sector $i$ and aggregate inflation). In the one sector model, the aggregate real reset price is simply a function of inflation $\left(\bar{x}_{t}=\frac{1-\omega}{\omega} \pi_{t}\right)$. Given the fact that the inflation gaps in the sectors with lower hazard rates take longer to close, reset price in the SW-MC adjusts more sluggishly than in the SW model.

\section{Robustness}

The aim of this section is to show that the main conclusions of the paper are not an artifact of the assumed distribution of price spells and hold even 
in simple two sector models. I will also check the robustness of my results to an alternative way of modelling heterogeneity in price stickiness using the Generalised Taylor Economy (GTE) (see Dixon and Kara (2010)).

\subsection{Two-sector MCs}

Simple two-sector MCs in which the sectors have equal shares are considered. The assumed relative degree of price stickiness in the two sectors, defined by $R S=\omega_{1} / \omega_{2}$, is varied by changing the parameters indicating the degree of price stickiness in the sectors (i.e. $\omega_{1}$ and $\omega_{2}$ ) across a range of values, while assuming the overall degree of price stickiness, as measured by $\kappa=\frac{1}{2} \sum_{i=1}^{2} 1 / \omega_{i}$, is the same as that implied by the SW model $(1 / \omega)$. In all cases prices in sector 1 are more flexible than prices in sector 2. Assuming $R S=1$ gives the SW case. Each of the resulting models is then estimated, as described in Section $3 .^{7}$

The results from this experiment suggest that the required standard deviations of price mark-up shocks and the standard deviation of reset price inflation become smaller, as relative price stickiness increases. This is true even though inflation's persistence in the two-sector economies is more or less the same as that in the SW. The results further suggest that reset price inflation becomes more persistent as relative price stickiness increases. These findings are consistent with the findings obtained using the SW-MC. With an increased mean preserving spread, prices in the sector with relatively flexible prices become more flexible, while prices in the sector with relatively sticky

\footnotetext{
${ }^{7}$ In each case, the performance of the two-sector model at the macro level with that of the SW is compared using Bayes Factors. Results (not reported) suggest the two-sector models perform as well as the one-sector SW model in terms of Bayes Factors.
} 
prices become stickier. Increased price flexibility in the sector with relatively flexible prices increases the variability of the average price level in this sector and, in turn, the variability of inflation. Therefore, the required size of price mark-up shocks and, consequently, the standard deviation of reset price inflation becomes smaller, as relative price stickiness increases. Finally, reset price inflation becomes more persistent since prices in the sticky price sector become stickier, as the mean preserving spread increases. As a consequence, the inflation gap in the sticky sector takes longer to close, leading to a more persistent reset price. Figure A.1 in Appendix A.3 illustrates these points.

The above results confirm the finding that there is a tight link between heterogeneity in price stickiness and the size of price mark-up shocks and that allowing even a small degree of heterogeneity improves the performance of the model. If the heterogeneity in price stickiness in the model is sufficiently large, a simple two-sector MC can match the modest persistence in actual inflation as well as the low variability of reset price inflation relative to actual inflation. Micro evidence on prices does suggest that there is a significant degree of heterogeneity in price stickiness.

\subsection{The GTE}

It may be useful to note that the type of price stickiness also matters for the results but not as significantly as the heterogeneity in price stickiness. To show this, I estimate the model by replacing the MC with the Generalised Taylor Economy (GTE) (see Dixon and Kara (2010)), in which there are many sectors, each with a Taylor-style contract. While the main results remain unchanged, the standard deviation of price mark-up shocks is slightly higher in the GTE $(0.52 \%)$ than in the $\mathrm{MC}(0.33 \%)$. This is because selection 
for older prices is stronger in the GTE than in the MC. This is true since although in both models resetting firms are mostly drawn from sectors with relatively more flexible prices, in the GTE, within each sector, price-changing firms are always the ones whose prices have been in place for longest. As a consequence, the sectoral price levels in the GTE do not change as much as they do in the MC. Thus, the GTE requires larger price mark-up shocks to match the volatility of inflation. These results reinforce the insight that the selection effect is the driving force behind the results.

\section{Summary and Conclusions}

The Smets and Wouters (2007) model has been reformulated to account for the heterogeneity in price stickiness observed in the data. Price stickiness is modelled according to the Multiple Calvo (MC) approach proposed in Carvalho (2006). The MC consists of many sectors, each with a Calvo-style contract. The share of each sector is calibrated according to the microevidence on prices. The resulting model is estimated using US data from 1990 to 2009.

I have first established that the new model fits the macroeconomic data as well as the Smets and Wouters (2007) model and then show that accounting for the heterogeneity in price stickiness suggested by micro evidence on prices helps to overcome two recent criticisms of the New Keynesian models. These criticisms are, first, that the Smets and Wouters model relies on unrealistically large price mark-up shocks to explain the data on inflation; and, second, that reset price inflation implied by the model is too volatile relative to what we see in the data. The SW with the MC accounts for the observed 
inflation dynamics with much smaller price mark-up shocks and comes close to matching the data on reset inflation.

The failure of the Smets and Wouters model is a consequence of generating far too much persistence in inflation. To match the persistence and volatility of inflation, the model assumes large and temporary price mark-up shocks. However, these shocks lead to implausibly volatile reset price inflation. The reformulated Smets and Wouters model with heterogeneity in price stickiness performs better since the price level changes more in response to temporary shocks in this model, which reduces the need for large price mark-up shocks. This is true since in the new model the sectors with more flexible prices are predominant in the price adjustment process, as the resetting firms are chosen disproportionately from sectors with more flexible prices. With lower price stickiness, the average price levels in these sectors change more in response to temporary shocks, resulting in more volatile inflation. As a result, given that price mark-up shocks directly hit reset prices, smaller price mark-up shocks mean that reset price inflation is less volatile in the version of the SW model with heterogeneity in price stickiness than without.

These findings clearly show that incorporating recent micro evidence on prices into existing New Keynesian models can significantly improve the performance of these models. In this paper, following Smets and Wouters (2007), wages are assumed to be set according to the Calvo scheme. Given the above findings, accounting for heterogeneity in wage contracts may help to address another criticism by Chari, Kehoe, and McGrattan (2009) regarding an implausibly large variance of wage mark-up shocks. Unfortunately, however, micro evidence on wages is scarce. Thus, this calls for more research to de- 
termine the shape of the distributions of wage durations. Finally, reset price inflation may be a useful concept in the formulation of monetary policy. I leave this issue as a matter of future research. 


\section{References}

Bils, M., Klenow, P., Malin, B., 2012. Reset price inflation and the impact of monetary policy shocks. American Economic Review 102 (6), 2798-2825.

Carvalho, C., 2006. Heterogeneity in price stickiness and the real effects of monetary shocks. Frontiers of Macroeconomics 2 (1).

Carvalho, C., Schwartzman, F. F., 2014. Selection and monetary nonneutrality in time-dependent pricing models. FRB Richmond Working Paper (12-09).

Chari, V. V., Kehoe, P. J., McGrattan, E. R., 2009. New Keynesian models: Not yet useful for policy analysis. American Economic Journal: Macroeconomics 1 (1), 242-66.

Christiano, L. J., Eichenbaum, M., Evans, C. L., 2005. Nominal rigidities and the dynamic effects of a shock to monetary policy. Journal of Political Economy 113 (1), 1-45.

Dixon, H., Kara, E., 2010. Can we explain inflation persistence in a way that is consistent with the micro-evidence on nominal rigidity? Journal of Money, Credit and Banking 42 (1), 151 - 170.

Kimball, M., 1995. The quantitative analytics of the basic neomonetarist model. Journal of Money, Credit and Banking 27 (4), 1241-1277.

Klenow, P., Malin, B., 2011. Microeconomic evidence on price-setting. In: Friedman, B., Woodford, M. (Eds.), Handbook of Monetary Economics. Elsevier, Amsterdam, pp. 231-284.

Klenow, P. J., Kryvtsov, O., 2008. State-dependent or time-dependent pricing: Does it matter for recent U.S. inflation? The Quarterly Journal of 
Economics 123 (3), 863-904.

Levin, A. T., Lopez-Salido, J. D., Nelson, E., Yun, T., 2008. Macroeconometric equivalence, microeconomic dissonance, and the design of monetary policy. Journal of Monetary Economics 55 (Supplement 1), S48 - S62.

Mankiw, N. G., Reis, R., 2002. Sticky information versus sticky prices: A proposal to replace the New Keynesian Phillips curve. The Quarterly Journal of Economics 117 (4), 1295-1328.

Smets, F., Wouters, R., 2003. An estimated dynamic stochastic general equilibrium model of the Euro area. Journal of the European Economic Association 1 (5), 1123-1175.

Smets, F., Wouters, R., 2007. Shocks and frictions in US business cycles: A Bayesian DSGE approach. American Economic Review 97 (32), 586-607. 
Table 1: Prior and Posterior Estimates of Structural Parameters

\begin{tabular}{|c|c|c|c|c|c|c|c|}
\hline & \multicolumn{3}{|c|}{ Prior Distribution } & \multicolumn{3}{|c|}{$\begin{array}{l}\text { Posterior Distribution } \\
\text { SW }\end{array}$} & $\mathrm{MC}$ \\
\hline & type & Mean & St. Dev. & Mean & St. Dev. & Mean & St. Dev \\
\hline$\varphi$ & Normal & 4.00 & 1.50 & 6.29 & 1.16 & 6.53 & 0.01 \\
\hline$h$ & Beta & 0.70 & 0.10 & 0.68 & 0.04 & 0.69 & 0.04 \\
\hline$\xi_{w}$ & Beta & 0.50 & 0.10 & 0.87 & 0.03 & 0.88 & 0.03 \\
\hline$\sigma_{l}$ & Normal & 2.00 & 0.75 & 1.24 & 0.35 & 1.27 & 0.35 \\
\hline$\omega$ & Beta & 0.50 & 0.10 & 0.25 & 0.04 & - & - \\
\hline$\psi$ & Beta & 0.50 & 0.15 & 0.64 & 0.12 & 0.64 & 0.13 \\
\hline$\Phi$ & Normal & 1.25 & 0.12 & 1.63 & 0.10 & 1.70 & 0.09 \\
\hline$r_{\pi}$ & Normal & 1.50 & 0.25 & 1.22 & 0.16 & 1.24 & 0.18 \\
\hline$\rho$ & Beta & 0.75 & 0.10 & 0.95 & 0.01 & 0.95 & 0.01 \\
\hline$r_{y}$ & Normal & 0.12 & 0.05 & 0.16 & 0.03 & 0.15 & 0.04 \\
\hline$r_{\triangle y}$ & Normal & 0.12 & 0.05 & 0.04 & 0.01 & 0.04 & 0.01 \\
\hline$\alpha$ & Normal & 0.30 & 0.05 & 0.21 & 0.02 & 0.21 & 0.02 \\
\hline $\bar{\Pi}$ & Gamma & 0.62 & 0.10 & 0.45 & 0.04 & 0.44 & 0.03 \\
\hline$\overline{\mathrm{E}}$ & Normal & 0.00 & 2.00 & -2.57 & 0.82 & -2.53 & 0.90 \\
\hline$\epsilon_{p}$ & Normal & 35.0 & 9.00 & 43.04 & 8.06 & 47.31 & 7.01 \\
\hline $\bar{\gamma}$ & Normal & 0.40 & 0.10 & 0.26 & 0.02 & 0.26 & 0.03 \\
\hline
\end{tabular}

Notes: SW-MC denotes the baseline model, i.e., Smets and Wouters' (2007) model with heterogeneity in price stickiness. SW refers to Smets and Wouters' original formulation. In the SW-MC, the share of each sector is calibrated according the Bils and Klenow (2004) dataset, while the Calvo hazard rate $(\omega)$ in the SW model is estimated. The columns 'Mean' and 'St. Dev.' list the means and the standard deviations of the prior and posterior distributions. 
Table 2: Prior and Posterior Estimates of Shock Processes

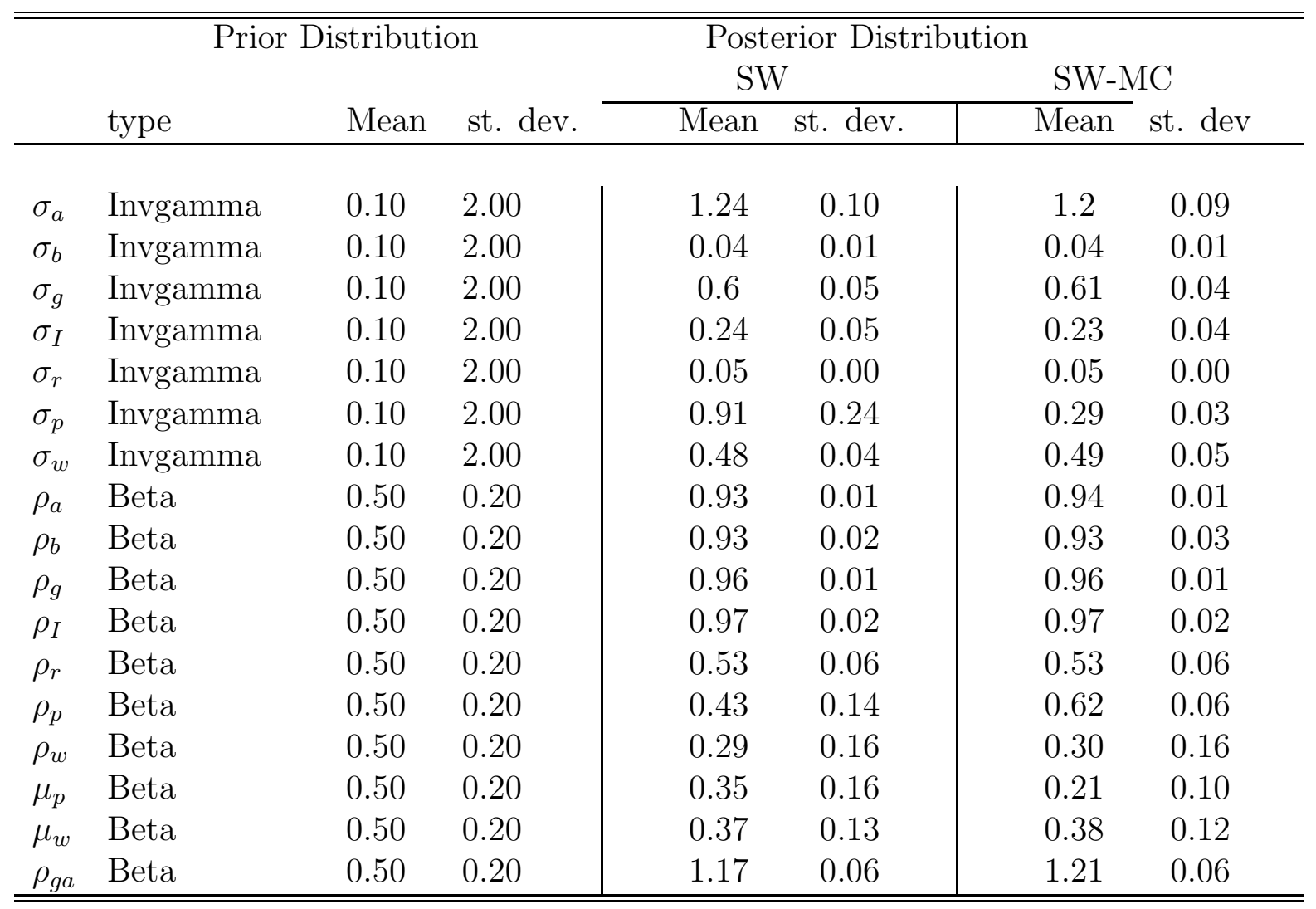

Notes: See the description notes in the previous table. 
Table 3: Summary Statistics for the models

\begin{tabular}{lccc}
\hline \hline Statistics & Data & SW & SW-MC \\
\hline (1) Log Marginal Data Density & - & -713.35 & -712.89 \\
(2) Bayes Factor versus SW & - & 1.00 & $e^{0.46}$ \\
Standard Deviations & & & \\
(3) Output Growth & 1.85 & 1.97 & 1.98 \\
(4) Consumption Growth & 0.45 & 0.71 & 0.71 \\
(5) Price Inflation & 0.33 & 0.33 & 0.35 \\
(5) Wage Inflation & 0.80 & 0.91 & 0.90 \\
(6) Investment & 1.88 & 3.38 & 3.35 \\
(7) Interest Rate & 0.34 & 0.30 & 0.30 \\
(8) Labour & 3.60 & 3.95 & 3.90 \\
\hline \hline
\end{tabular}

Notes: Row (1) reports the Marginal density for each model and Row (2) the corresponding Bayes Factors by taking the SW as a reference model. Rows (3)-(8) report the standard deviations from the model and from the data. In Rows (3)-(8), statistics are averages across 100 model simulations, each of 119 periods. Increasing the number of simulations to 500 or 1000 draws does not change the results. 
Table 4: Summary Statistics for Inflation and Reset Price Inflation

\begin{tabular}{lccc}
\hline \hline Statistics & Data & SW & SW-MC \\
\hline Standard Deviation of $\pi$ & $0.33 \%$ & $0.35 \%$ & $0.35 \%$ \\
Serial Correlation of $\pi$ & 0.13 & 0.13 & 0.13 \\
& & & \\
Standard deviation of $\pi^{*}$ & $0.66 \%$ & $1.61 \%$ & $0.77 \%$ \\
Serial Correlation of $\pi^{*}$ & 0.06 & -0.42 & -0.19 \\
$1-$ year cumulative $\pi$ & & & \\
$\frac{1-\text { year cumulative } \pi^{*}}{1-5}$ & & 3.8 & 2.2 \\
\hline \hline
\end{tabular}

Notes: In Rows, (1)-(4), statistics are averages across 100 model simulations, each of 119 periods. Increasing the number of simulations to 500 or 1000 draws does not change the results. The data statistics are reported in Column (1), while the models' statistics are reported in Columns (2) and (3). 


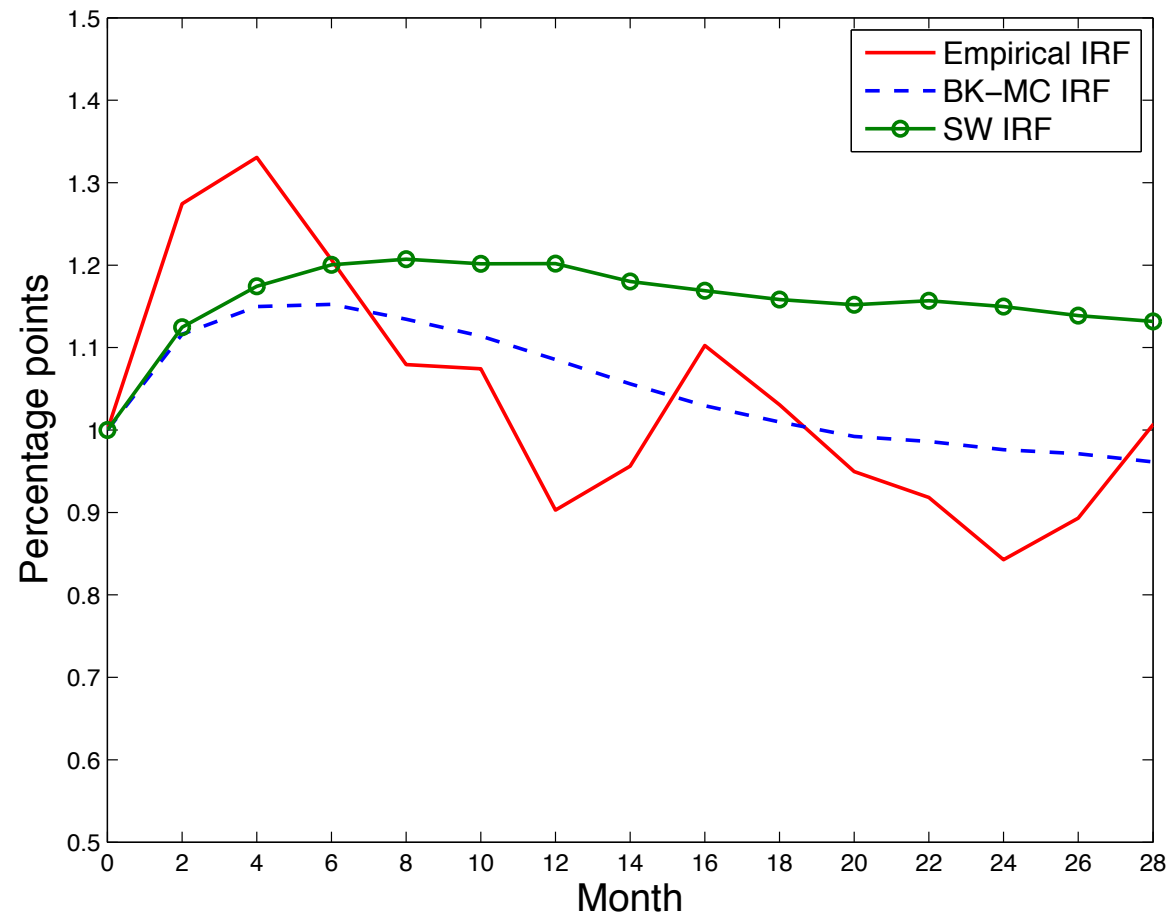

Figure 1: Impulse Response Functions (IRF) of Reset Price Inflation: Empirical Response vs Model Responses

Notes: Plotted are accumulated responses to $\operatorname{ARMA}(6,6)$ for reset price inflation. The empirical IRF is estimated by BKM and is based on CPI-RDB data for all items. 